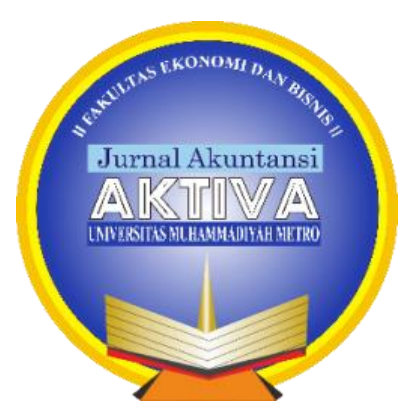

Jurnal Akuntansi AKTIVA, Vol 1, No. 2 Oktober 2020

\title{
PERANAN PENGAWASAN DAN PENYELAMATAN KREDIT DALAM MEMINIMALKAN KEMUNGKINAN GAGAL BAYAR PADA PENYELESAIAN KREDIT MODAL KERJA (STUDI KASUS PADA PT BPR EKA BUMI ARTHA METRO)
}

\author{
${ }^{1 *}$ Herni Kurniawati, ${ }^{2}$ Nedi Hendri ${ }^{3}$ Elmira Febri Darmayanti \\ ${ }^{1,2,3}$ Fakultas Ekonomi dan Bisnis Universitas Muhammadiyah Metro, Lampung, Indonesia \\ 1email: herni310396@gmail.com
}

\begin{abstract}
The purpose of this study was to find out how the role of supervision and credit rescue in minimizing the possibility of default on the completion of working capital loans at PT BPR Eka Bumi Artha Metro. The method in this study is descriptive qualitative. Data collection techniques used are observation, interview, documentation. The analytical tool used is descriptive method. The results of this study indicate that the credit control section has performed its role to the maximum extent possible, but the risk of external factors cannot be avoided. Whereas the credit rescue department has carried out its role to the maximum extent possible in returning nonperforming loans by way of negotiating settlement or by selling voluntary collateral assets, thereby reducing the rate of increase in NPLs so that credit quality is maintained. This can be seen from the good credit quality in 2013 and 2014, namely the NPL is $1 \%$ below the maximum limit of 5\% in accordance with Bank Indonesia regulations. Furthermore in 2015NPL increased by 5\% from the previous year, which is $9 \%$ which means that it is above $4 \%$ of the maximum credit limit. And in 2016 and 2017 NPL decreased by 1\% from the previous year, which is to 8\%, which means above $3 \%$ the maximum credit limit. The credit supervision and rescue team has sought to reduce the rate of increase in NPLs so that credit quality is maintained. This has been provenbecause in 2016 and 2017 the quality of NPLs decreased $1 \%$ from the previous year which experienced a $5 \%$ increase in NPLs.

Keywords: Credit Supervision and Rescue, Troubled Credit, Working Capital.
\end{abstract}

\begin{abstract}
ABSTRAK
Tujuan dari penelitian ini adalah untuk mengetahui bagaimana peranan pengawasan dan penyelamatan kredit dalam meminimalkan kemungkinan gagal bayar pada penyelesaian kredit modal kerja pada PT BPR Eka Bumi Artha Metro. Metode pada penelitian ini adalah deskriptif kualitatif. Teknik pengumpulan data yang digunakan adalah observasi, interview,dan dokumentasi. Alat analisis yang digunakan adalah metode deskriptif. Hasil dari penelitian ini menunjukkan bahwa bagian pengawasan kredit telah melakukan peranannya semaksimal mungkin, namun risiko dari faktor ekternal tidak dapat terhindarkan. Sedangkan bagian penyelamatan kredit telah melakukan peranannya semaksimal mungkin dalam pengembalian kredit bermasalah dengan cara penyelesaian secara negosiasi atau dengan cara melakukan penjualan asset jaminan secara sukarela sehingga menekan tingkat kenaikan
\end{abstract}

\section{2 | Jurnal Akuntansi AKTIVA}


NPL agar kualitas kredit tetap terjaga. Hal ini dapat dilihat dari kualitas kredit pada tahun 2013 dan 2014 yang baik yaitu NPL berada 1\% dibawah batas maksimal yaitu 5\% sesuai ketentuan Bank Indonesia. Selanjutnya pada tahun 2015 NPL mengalami kenaikan sebesar 5\% dari tahun sebelumnya, yaitu menjadi 9\% yang berarti diatas 4\% batas maksimal kredit. Dan pada tahun 2016 dan 2017 NPL mengalami penurunan sebesar 1\% dari tahun sebelumnya, yaitu menjadi $8 \%$ yang berarti diatas 3\% batas maksimal kredit. Tim pengawasan dan penyelamatan kredit telah berupaya untuk menekan tingkat kenaikan NPL tersebut agar kualitas kredit tetap terjaga, Hal ini telah terbukti karena pada tahun 2016 dan 2017 kualitas NPL menurun 1\% dari tahun sebelumnya yang mengalami kenaikan NPL 5\%.

Kata Kunci: Pengawasan dan Penyelamatan Kredit, Kredit Bermasalah, Kredit Modal Kerja.

\section{PENDAHULUAN}

Bidang perkreditan di Indonesia sampai saat ini masih merupakan bidang kegiatan perbankan yang paling utama, karena pendapatan terbesar dalam usaha perbankan berasal dari kegiatan usaha kredit. Kredit adalah penyediaan uang atau tagihan yang dapat dipersamakan dengan itu, berdasarkan persetujuan atau kesepakatan pinjam-meminjam dengan pihak lain yang mewajibkan pihak peminjam untuk setelah jangka waktu tertentu dengan pemberian bunga. (Undang-Undang Perbankan No.10 Tahun 1998 tentang Perubahan Atas Undang-Undang No. 7 Tahun 1992).

Fasilitas kredit yang disediakan bank guna memenuhi kebutuhan masyarakat digolongkan menjadi tiga berdasarkan tujuan kegunaannya yaitu, Kredit Investasi, Kredit Modal Kerja dan Kredit Konsumtif. Kredit modal kerja diberikan oleh bank dalam rangka memberikan kebutuhan modal kerja perusahaan. (Ismail, 2012: 191). Kemungkinan resiko yang timbul dalam penyaluran kredit adalah terjadi gagal bayar pada penyelesaian kredit atau transaksi pembayaran kembali yang atas kredit dalam kondisi tidak terbayar, dengan kata lain ada suatu indikasi terjadi kredit bermasalah. (Purwanti, 2016). Menurut Verawaty, dkk (2017:82) Resiko kredit semakin besar bila bank tidak mampu meningkatkan atau memperbaiki kualitas kredit yang disalurkan, menunjukkan kinerja bank yang buruk. Kredit dikategorikan sebagai kredit bermasalah atau non-performing loan (NPL) adalah apabila kualitas kredit tergolong pada tingkat kolektibitas kurang lancar, diragukan, atau macet. Tujuan penetapan kolektibilitas kredit adalah untuk mengetahui kualitas kredit sehingga bank dapat mengantisipasi risiko kredit secara dini karena risiko kredit dapat mempengaruhi kelangsungan usaha bank. Di samping penetapan kolektibilitas kredit digunakan untuk menetapkan tingkat cadangan potensi kerugian akibat kredit bermasalah (Hermansyah, 2008: 75).

PT BPR Eka Bumi Artha merupakan lembaga keuangan yang memberikan fasilitas kredit yang cukup besar kepada nasabahnya. PT BPR Eka Bumi Artha juga masih memiliki masalah mengenai pengembalian kredit yang macet. Dapat dilihat di tabel kualitas kredit atau kolektibilitas kredit berikut ini:

\section{3 | Jurnal Akuntansi AKTIVA}




\begin{tabular}{|c|c|c|c|c|c|}
\hline \multicolumn{6}{|c|}{$\begin{array}{c}\text { Tabel 1. Kolektibilitas Kredit Produktif } \\
\text { PT BPR Eka Bumi Artha Tahun } 2013 \text { s.d } 2017\end{array}$} \\
\hline $\begin{array}{c}\text { Kualitas } \\
\text { Kredit }\end{array}$ & 2013 & 2014 & 2015 & 2016 & 2017 \\
\hline Lancar & $\begin{array}{l}163.388 \\
822\end{array}$ & $\begin{array}{l}174.845 . \\
717\end{array}$ & $\begin{array}{l}128.974 \\
481\end{array}$ & $\begin{array}{l}106.869 \\
850\end{array}$ & $\begin{array}{l}85.854 \\
364\end{array}$ \\
\hline $\begin{array}{l}\text { Kurang } \\
\text { Lancar }\end{array}$ & $\begin{array}{l}2.086 .91 \\
9\end{array}$ & $\begin{array}{l}3.301 .33 \\
2\end{array}$ & $\begin{array}{l}1.643 .99 \\
6\end{array}$ & 659.009 & $\begin{array}{l}871.99 \\
8\end{array}$ \\
\hline Diragukan & $\begin{array}{l}2.615 .61 \\
7\end{array}$ & $\begin{array}{l}1.575 .50 \\
8\end{array}$ & $\begin{array}{l}3.838 .21 \\
7\end{array}$ & $\begin{array}{l}1.076 .74 \\
4\end{array}$ & $\begin{array}{l}1.181 .7 \\
62\end{array}$ \\
\hline Macet & 528.342 & $\begin{array}{l}2.080 .16 \\
0\end{array}$ & $\begin{array}{l}6.513 .45 \\
9\end{array}$ & $\begin{array}{l}6.721 .14 \\
0\end{array}$ & $\begin{array}{l}4.729 .6 \\
78\end{array}$ \\
\hline $\begin{array}{l}\text { Jumlah } \\
\text { Kredit yang }\end{array}$ & $\begin{array}{l}168.619 \\
701\end{array}$ & $\begin{array}{l}181.802 . \\
717\end{array}$ & $\begin{array}{l}140.970 . \\
153\end{array}$ & $\begin{array}{l}115.326 \\
742\end{array}$ & $\begin{array}{l}92.637 \\
802\end{array}$ \\
\hline
\end{tabular}

Sumber : PT BPR Eka Bumi Artha

Dapat dilihat dari jumlah kredit yang disalurkan di PT BPR Eka Bumi Artha pada tahun 2013 sampai dengan tahun 2014 mengalami kenaikan, namun pada tahun 2015 sampai tahun 2017 kredit yang disalurkan terus mengalami penurunan. Dan dapat dilihat pula kemungkinan gagal bayar atau kredit macet di PT BPR Eka Bumi Artha pada tahun 2014 sampai tahun 2016 mengalami kenaikan, namun pada tahun 2017 mengalami penurunan. Dapat dilihat bahwa peran pengawasan dan penyelamatan kredit sangat dibutuhkan disini karena bagian pengawasan dan penyelamatan kredit akan berupaya untuk menjaga asset perusahaan yang telah disalurkan melalui kredit namun risiko dari faktor eksternal seperti usaha debitur yang telah tutup, situasi kondisi ekonomi secara global yang tidak dapat dihindarkan. Pengawasan yang berkelanjutan dapat dilakukan dengan cara melakukan komunikasi dengan debitur untuk menanyakan kondisi usaha, perkembangan usaha, dan kendala yang dihadapi debitur saat ini. Selain itu juga dapat melakukan kunjungan kelapangan untuk melihat langsung kondisi usaha debitur, sehingga bagian pengawasan dan penyelamatan kredit dapat mengetahui apakah permasalahan kredit yang terjadi murni karena aktivitas usaha debitur atau karena kecurangan yang dilakukan debitur terhadap fasilitas kredit yang telah diterimanya.

\section{KAJIAN TEORITIK}

\section{Teori Stewardship}

Teori stewardship merupakan teori yang dicetuskan oleh Donaldson dan Davis (1989) tentang situasi para manajer yang memiliki motivasi dalam bekerja, tidak hanya karena tujuan individu tetapi lebih memprioritaskan pada kepentingan organisasi. Dasar dari teori ini yaitu psikologi dan sosiologi yang ditujukan untuk memotivasi para eksekutif sebagai steward untuk bertindak sesuai dengan keinginan principal tanpa mengesampingkan tujuan organisasinya untuk mencapai target yang telah 
ditentukan. (Riyadi dan Yulianto, 2014). Implikasi teori stewardship pada penelitian ini yaitu didasarkan pada hubungan antara pemodal (bank) dengan pengelola modal (nasabah) sebelum dan sesudah melakukan pembiayaan. Pihak bank selaku steward akan melakukan apa yang diinginkan oleh nasabah atau principal. Kebutuhan nasabah untuk mendapatkan pembiayaan/modal kerja akan dibantu oleh pihak bank dengan menawarkan berbagai jenis pembiayaan yang sesuai dan melakukan apa yang diinginkan oleh nasabah terkait pembiayaan. Namun, bank tidak melupakan tujuan yaitu mensejahterakan masyarakat dan mendapatkan laba dari aktivitas operasionalnya. Sebelum memberikan keputusan pembiayaan, perlu mempertimbangan risiko yang akan diterima oleh bank.

\section{Kredit Bermasalah}

Kredit bermasalah adalah kredit dengan kualitas kurang lancar, diragukan dan macet. Semakin tinggi rasio NPL, maka akan semakin buruk kualitas kredit bank yang menyebabkan jumlah kredit bermasalah semakin besar. Jika Rasio NPL besar maka bank harus menanggung kerugian dalam kegiatan operasionalnya sehingga berpengaruh kredit yang diberikan kepada pihak ketiga tidak termasuk kredit kepada bank lain (Verawaty, dkk, 2017:86)

\section{Pengawasan Kredit}

Pengawasan Kredit adalah usaha untuk mengendalikan pelaksanaan kredit oleh bank dan nasabah agar persyaratan dan target yang diasumsikan dapat dipenuhi sebagai dasar persetujuan kredit. (Veithzal, 2006:564)

\section{Penyelamatan Kredit}

Penyelamatan kredit bermasalah merupakan upaya-upaya bank untuk melancarkan kembali kredit yang telah tergolong tidak lancar, diragukan, atau bahkan telah tergolong macet untuk dikembalikan menjadi kredit lancar, sehingga debitur kembali mempunyai kemampuan untuk membayar kepada bank, baik bunga maupun pokoknya. Meskipun bank telah melakukan analisis yang cermat, risiko kredit bermasalah juga mungkin terjadi. Tidak ada satupun bank yang tidak memiliki kredit bermasalah, karena tidak mungkin dari semua kredit yang disalurkan semuanya lancar. Ismail (2012).

\section{METODELOGI PENELITIAN}

Penelitian ini menggunakan metode penelitian deskriptif kualitatif. Objek dalam penelitian ini yaitu pada bagian pengawasan dan penyelamatan kredit untuk mengetahui peranannya dalam meminimalkan kemungkinan gagal bayar pada penyelesaian kredit modal kerja. Sedangkan lokasi 
penelitian yaitu di PT BPR Eka Bumi Artha Metro tepatnya di Jln. Ahmad Yani No. 70, Metro, Lampung. Responden penelitian ini sebanyak 16 karyawan yang diwawancarai untuk mengetahui peranan pengawasan dan penyelamatan kredit dalam meminimalkan kemungkinan gagal bayar pada penyelesaian kredit modal kerja. Dalam wawancara ini, peneliti akan mewawancarai 8 karyawan bagian kredit dan 8 karyawan bagian pengawasan dan penyelamatan kredit.

Teknik analisis data yang digunakan dalam penelitian ini adalah menggunakan langkah-langkah sebagai berikut :

1. Data Colection: Kegiatan pengumpulan data pada penelitian ini adalah dengan menggunakan wawancara dan studi dokumentasi.

2. Data Reduction: Reduksi dilakukan sejak pengumpulan data dimulai dengan membuat ringkasan, mengkode, menelusur tema, membuat gugus-gugus, menulis memo dan sebagainya dengan maksud menyisihkan data atau informasi yang tidak relevan.

3. Display Data, adalah pendeskripsian sekumpulan informasi tersusun yang memberikan kemungkinan adanya penarikan kesimpulan dan pengambilan tindakan. Penyajian data kualitatif disajikan dalam bentuk teks naratif. Penyajiannya juga dapat berbentuk matrik, diagram, tabel dan bagan.

4. Conclution Drawing and Verfication: Merupakan kegiatan akhir dari analisis data. Penarikan kesimpulan berupa kegiatan interprestasi, yaitu menemukan makna data yang telah disajikan.

\section{HASIL DAN PEMBAHASAN}

\section{Gambaran Umum Prosedur Pemberian dan Pelaksanaan Kredit UMKM}

Pemberian kredit harus mengikuti prosedur pemberian kredit yang sehat, yang terdiri dari:
a. Permohonan kredit
b. Tahap Analisis Kredit
c. Tahap Persetujuan Kredit

\section{Risiko Kredit}

Tabel 2. Kolektibilitas Kredit Produktif PT BPR Eka Bumi Artha Tahun 2013 s.d 2017

\begin{tabular}{|l|r|r|r|r|r|}
\hline Kualitas Kredit & \multicolumn{1}{|c|}{$\mathbf{2 0 1 3}$} & $\mathbf{2 0 1 4}$ & $\mathbf{2 0 1 5}$ & \multicolumn{1}{|c|}{$\mathbf{2 0 1 6}$} & \multicolumn{1}{|c|}{$\mathbf{2 0 1 7}$} \\
\hline Lancar & 163.388 .822 & 174.845 .717 & 128.974 .481 & 106.869 .850 & 85.854 .364 \\
\hline Kurang Lancar & 2.086 .919 & 3.301 .332 & 1.643 .996 & 659.009 & 871.998 \\
\hline Diragukan & 2.615 .617 & 1.575 .508 & 3.838 .217 & 1.076 .744 & 1.181 .762 \\
\hline Macet & 528.342 & 2.080 .160 & 6.513 .459 & 6.721 .140 & 4.729 .678 \\
\hline
\end{tabular}




\begin{tabular}{|l|c|c|c|c|c|}
\hline Kualitas Kredit & $\mathbf{2 0 1 3}$ & $\mathbf{2 0 1 4}$ & $\mathbf{2 0 1 5}$ & $\mathbf{2 0 1 6}$ & $\mathbf{2 0 1 7}$ \\
\hline $\begin{array}{l}\text { Jumlah Kredit yang } \\
\text { Disalurkan }\end{array}$ & 168.619 .701 & 181.802 .717 & 140.970 .153 & 115.326 .742 & 92.637 .802 \\
\hline
\end{tabular}

Sumber : PT BPR Eka Bumi Artha

Berdasarkan tabel diatas, dapat dilihat data mengenai kolektibilitas atau kualitas kredit produktif yaitu kredit modal kerja PT BPR Eka Bumi Artha selama lima tahun terakhir yaitu tahun 2013, 2014, 2015, 2016 dan 2017. Berdasarkan tabel diatas dapat dilihat bahwa jumlah kredit yang disalurkan selama tahun 2013 sampai tahun 2014 mengalami peningkatan, tetapi dari tahun 2015 sampai dengan tahun 2017 jumlah kredit yang disalurkan mengalami penurunan. Kemudian dapat dilihat pula bahwa kredit macet selama tahun 2013 sampai dengan 2016 terus mengalami peningkatan, tetapi ditahun 2017 kredit macet mengalami penurunan. Hal ini disebabkan karena kondisi ekonomi secara makro memang selalu mengalami penurunan khususnya untuk Kredit Usaha Mikro Kecil dan Menengah. Sedangkan di PT BPR Eka Bumi Artha Portofolio kredit yang diberikan porsinya lebih banyak disalurkan untuk kredit konsumsi (Kredit Pegawai) dibandingkan dengan UMKM yang hanya mendapatkan porsi sekitar 10\% dari total Outstanding kredit yang disalurkan.

\section{Gambaran Umum Pelaksanaan Pengawasan dan Penyelamatan Kredit}

Dalam rangka pelaksanaan pengawasan kredit telah dibentuk Divisi Pengawasan dan Penyelamatan Kredit yang bertanggung jawab langsung kepada Direktur Utama. Pengawasan kredit berperan mengawasi kredit yang telah disalurkan oleh perusahaan kepada debitur agar kredit dipergunakan sesuai dengan peruntukannya dan apabila terjadi penyelewangan pengunaan kredit maka bagian pengawas kredit memberikan informasi awal terhadap risiko kredit (gagal bayar/kerugian perusahaan) terhadap atasan langsung yang akan diteruskan kepada direksi atau pemegang keputusan perusahaan. Bagian Pengawasan Kredit akan melaporkan kepada atasan terkait risiko yang akan timbul dan memberikan saran untuk penyelesaian sebelum terjadi kerugian lebih besar, laporan tersebut kemudian diteruskan oleh atasan langsung kepada Direksi secara tertulis. Sedangkan peyelamatan kredit berperan menyelesaikan kredit yang dianggap memilki risiko kredit tinggi dan tidak dapat diselesaikan atau ditangani oleh kantor operasional atau kantor cabang. Penyelamatan kredit menyelesaikan kredit bermasalah dengan cara mengembalikan dana kredit yang telah disalurkan kepada masyarakat dan telah dianggap sebagai kerugian perusahaan dengan jalur negosiasi atau secara peraturan hukum yang berlaku. Cara penyelesaian negosiasi dengan debitur agar segera melakukan pelunasan dengan sumber pendapatan yang dimiliki saat ini atau dengan cara melakukan penjualan asset jaminan secara sukarela. Jika langkah tidak dapat terselesaikan maka diambil jalan hukum dengan cara lelang jaminan melalui KPKNL (Kantor Pelayanan Kekayaan Negara dan Lelang). 


\section{PEMBAHASAN}

\section{Prosedur Pelaksanaan Kredit}

Sistem pemberian kredit yang dilakukan oleh PT BPR Eka Bumi Artha sudah baik karena telah mengacu dan sesuai pada Undang-Undang Perbankan Indonesia Nomor 10 tahun 1998 dalam pasal 8 tentang pemberian kredit. Selain itu dalam pemberian kredit di PT BPR Eka Bumi Artha juga sudah sangat baik. Hal ini dapat dilihat dalam proses pemberian kredit telah dilakukan dengan beberapa analisis untuk meyakinkan bahwa calon nasabah tersebut layak untuk mendapatkan kredit antara lain seperti : analisis 5C, analisis aspek pemasaran, analisis aspek teknis dan produksi, analisis aspek manajemen, analisis aspek legal/yuridis, analisis aspek keuangan, analisis aspek sosial ekonomi dan lingkungan, analisis aspek risiko, sehingga dalam proses pemberian kredit secara keseluruhan yang diterapkan sudah berjalan dengan efektif.

Hasil penelitian ini konsisten dengan yang dilakukan oleh Sari (2009) dengan hasil bahwa sistem pemberian kredit mikro yang dilakukan dengan jelas dalam pembagian tugas dan tanggungjawab masingmasing bagian telah dilakukan dengan baik karena dalam penerapan sistem pemberian kredit di Bank Rakyat Indonesiatelah sesuai dengan pedoman atau peraturan Undang-undang Perbankan No. 10 tahun 1998 dalam pasal 8 tentang pemberian kredit.

\section{Risiko Kredit}

Resiko kredit akan dihadapi oleh bank ketika nasabah (customer) gagal dalam membayar hutang atau kredit yang diterimanya pada saat jatuh tempo (Verawaty, 2017:82). Berdasarkan hasil wawancara yang dilakukan kepada Kanit UMKM di PT BPR Eka Bumi Artha, dapat diinformasikan bahwa perusahaan ini masih memiliki masalah mengenai pengembalian kredit yang macet. Dapat dilihat dihasil penelitian diatas bahwa jumlah kredit yang disalurkan selama 3 (tiga) tahun terakhir semakin mengalami penurunan, kemudian dapat dilihat pula bahwa kemungkinan gagal bayar atau kredit macet yang mengalami peningkatan ditahun 2013 sampai dengan 2016, sedangkan ditahun 2017 kredit macet mengalami penurunan.

Menurut Peraturan Bank Indonesia No.17/11/PBI/2015 tentang Perubahan Atas Peraturan Bank Indonesia No.15/15/PBI/2013 tentang Giro Wajib Minimum Bank Umum dalam Rupiah Dan Valuta Asing Bank Umum Konvensional bahwa Kredit akan digolongkan bermasalah (non performing loan) apabila telah masuk dalam kualitas kurang lancar, diragukan, dan macet, terhadap total kredit. Tujuan klasifikasi tersebut untuk menetapkan tingkat cadangan potensi kerugian akibat kredit bermasalah. Berikut ini tabel performance loan kredit produktif PT BPR Eka Bumi Artha Metro dari tahun 2013 sampai dengan 2017.

\section{8 | Jurnal Akuntansi AKTIVA}


Tabel 3. Performance Loan Kredit Produktif PT BPR Eka Bumi Artha Per 31 Desember 2013 s.d 2017

\begin{tabular}{|c|c|c|c|}
\hline Tahun & Lancar & Jumlah Kredit Disalurkan & Performance Loan \\
\hline 2013 & 163.388 .822 & 168.619 .701 & $96 \%$ \\
\hline 2014 & 174.845 .717 & 181.802 .717 & $96 \%$ \\
\hline 2015 & 128.974 .481 & 140.970 .153 & $91 \%$ \\
\hline 2016 & 106.869 .850 & 115.326 .742 & $92 \%$ \\
\hline 2017 & 85.854 .364 & 92.637 .802 & $92 \%$ \\
\hline
\end{tabular}

Sumber : Data diolah, 2018

Tabel 4. Tingkat Kolektibilitas Kredit Produktif PT BPR Eka Bumi Artha Per 31 Desember 2013 s.d 2017

\begin{tabular}{|c|c|c|}
\hline Tahun & Performance Loan & Non Performing Loan \\
\hline 2013 & $96 \%$ & $4 \%$ \\
\hline 2014 & $96 \%$ & $4 \%$ \\
\hline 2015 & $91 \%$ & $9 \%$ \\
\hline 2016 & $92 \%$ & $8 \%$ \\
\hline 2017 & $92 \%$ & $8 \%$ \\
\hline
\end{tabular}

Sumber : Data diolah, 2018

Berdasarkan dari hasil perhitungan terhadap tingkat kolektibilitas kredit modal kerja yang disalurkan oleh PT BPR Eka Bumi Artha dari tahun 2013 sampai dengan 2017 terlihat bahwa non performing loan ditahun 2015 sampai dengan 2017 telah melebihi batas maksimal NPL yang ditetapkan Bank Indonesia. Menurut Peraturan Bank Indonesia Nomor 15/2/PBI/2013 tentang Penetapan Status dan Tindak Lanjut Pengawasan Bank Umum Konvensional mengatakan bahwa batas maksimal Non Performing Loan adalah sebesar 5\%.

Bagian pengawasan dan penyelamatan kredit telah berupaya menjaga komunikasi dengan debitur untuk menanyakan kondisi usaha, perkembangan usaha dan kendala yang dihadapi saat ini. Bagian pengawasan dan penyelamatan kredit juga melakukan kunjungan kelapangan dan melihat langsung kondisi usaha, sehingga bagian pengawasan dan penyelamatan kredit dapat mengetahui apakah permasalahan kredit yang terjadi murni karena aktivitas usaha debitur atau karena kecurangan yang dilakukan debitur terhadap fasilitas kredit yang telah diterimanya. Jika memang terkait dengan aktivitas usaha, pendampingan yang akan dilakukan yaitu dengan memberikan masukan atau solusi yang dapat membantu debitur keluar dari permasalahan usaha yang dialaminya.

Berdasarkan dari hasil wawancara yang penulis dapatkan bahwa pengawasan dan penyelamatan kredit telah dilakukan semaksimal mungkin, namun risiko dari faktor eksternal tersebut tidak dapat terhindarkan. Diharapkan dengan adanya pengawasan perkreditan yang berkelanjutan akan makin 
meningkatkan efektivitas kegiatan perkreditan dimana NPL bank semakin turun dan berada dibawah batas maksimal NPL yang telah ditetapkan oleh Bank Indonesia. Hal ini sejalan dengan hasil penelitian yang dilakukan oleh Rosmalinda (2011) bahwa terdapat beberapa faktor yang menyebabkan terjadinya pembiayaan bermasalah, faktor tersebut antara lain ketidakjujuran dan keengganan nasabah berbagi keuntungan. Keseluruhan faktor tersebut terjadi karena rendahnya pengawasan dan prinsip kehati-hatian.

\section{Pelaksanaan Pengawasan dan Penyelamatan Kredit}

Pelaksanaan pengawasan dan penyelamatan kredit berpedoman pada standar kinerja peraturan Internal PT BPR Eka Bumi Artha antara lain PKPB (Pedoman Kebijakan Perkreditan), dan Pedoman Pengawasan Dan Penyelamatan Kredit Bank Eka. Dalam menyikapi kredit bermasalah, bagian pengawasan dan penyelamatan kredit berupaya untuk menyelesaikan kredit secepat mungkin agar tidak berlarut-larut dan tidak menimbulkan kerugian yang lebih besar. Berdasarkan hasil wawancara kepada Bapak Sujarwoto selaku Kabag Pengawasan dan Penyelamatan Kredit PT BPR Eka Bumi Artha serta berdasarkan penjelasan diatas, dapat disimpulkan bahwa pengawasan dan penyelamatan kredit memiliki peranan yang penting bagi pengembalian kredit bermasalah. Selain itu bagian pengawasan dan penyelamatan kredit berperan untuk pencegahan kemungkinan penyalahgunaan kredit, praktik pemberian kredit yang tidak sehat serta kemungkinan terjadinya kredit bermasalah yang dapat merugikan bank dimasa yang akan datang dapat diminimalkan. Penelitian ini sejalan dengan yang dilakukan oleh Saraswati (2012) yang menjelaskan tentang (1) pentingnya posisi keuangan bagi perbankan dalam menyetujui permohonan kredit, (2) prosedur penilaian laporan keuangan calon debitur oleh bank, (3) penilaian prinsip 5C calon debitur yang dilakukan oleh bank, (4) keefektivan pengawasan kredit, dan (5) meminimalisir atau mencegah terjadinya kredit macet oleh debitur yang dapat merugikan pihak bank sebagai debitur.

\section{DAFTAR PUSTAKA}

Hermansyah, 2008. Hukum Perbankan Nasional Indonesia, Edisi Revisi, Kencana Media Group, Jakarta.

Ismail. 2012. Akuntansi Bank Teori dan Aplikasi dalam Rupiah. Jakarta: Kencana Media Group Peraturan Bank Indonesia Nomor 15/2/PBI/2013 tentang Penetapan Status dan Tindak Lanjut Pengawasan Bank Umum Konvensional

Peraturan Bank Indonesia No.17/11/PBI/2015 tentang Perubahan Atas Peraturan Bank Indonesia No.15/15/PBI/2013

Purwanti, Yuli. 2016. Analisis Kinerja Auditor Internal Dalam Penyelesaian Kredit Bermasalah pada BPR Shinta Putra Kulon Progo. Skripsi Universitas Negeri Yogyakarta.

Rivai, Veithzal dan Andria Permata Veithzal. 2006. Credit Management Handbook (Teori, Konsep, Prosedur, dan Aplikasi Panduan Praktis Mahasiswa, Bankir, dan Nasabah). Jakarta: PT Raja Grafindo 
Riyadi, Slamet dan Yulianto, Agung. 2014. Pengaruh Pembiayaan Bagi Hasil, Pembiayaan Jual Beli, Financial to Deposit Ratio (FDR) dan Non Performing Financing (NPF) terhadap Profitabilitas Bank Umum Syariah di Indonesia. Accounting Analysis Journal. Fakultas Ekonomi Unnes, Semarang.

Rosmalinda, Upia. 2011. Prinsip Kehati-hatian Dalam Perspektif Pencegahan Pembiayaan Mudharabah Bermasalah Pada BPRS Bumi Rinjani Malang. Skripsi UIN Sunan Kalijaga, Yogyakarta.

Saraswati, Rosita Ayu. 2012. Peranan Analisis Laporan Keuangan, Penilaian Prinsip 5C Calon Debitur Dan Pengawasan Kredit Terhadap Efektivitas Pemberian Kredit Pada PD BPR Bank Pasar Kabupaten Temanggung. Jurnal Nominal Volume 1 Nomor 1 Universitas Negeri Yogyakarta.

Sari, Linda Mega. 2009. Penerapan Implementasi Pengendalian Internal dalam Sistem Pemberian Kredit Usaha Mikro Kecil Menengah pada PT BRI Persero, Tbk.

Undang-Undang Republik Indonesia Nomor 10 Tahun 1998 Tentang Perubahan Atas UndangUndang No. 7 Tahun 1992). Pasal 8 tentang Pemberian Kredit

Verawaty, dkk. 2017. Pengaruh Resiko Kredit, Likuiditas, Efisiensi Operasional dan Tingkat Ekonomi Makro Ekonomi Terhadap Kinerja Bank Pembangunan Daerah di Pulau Sumatera. Jurnal AKUISISI. Vol. 13, No. 1, April 2017. Hal. 81-90. 